
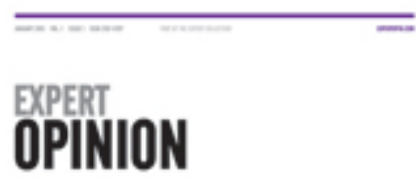

as touc bisonies

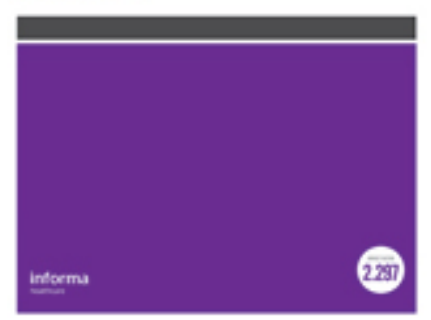

Please download and read the instructions before proceeding to the peer review

\title{
What can human blood-brain barrier models tell us about BBB function and drug discovery?
}

\begin{tabular}{|r|l|}
\hline Journal: & Expert Opinion On Drug Discovery \\
\hline Manuscript ID & EODC-2019--0031.R2 \\
\hline Manuscript Type: & Review (Invited) \\
\hline Keywords: & $\begin{array}{l}\text { blood-brain barrier, human in vitro models, drug discovery, BBB } \\
\text { function, stem cells }\end{array}$ \\
\hline
\end{tabular}

\section{SCHOLARONE ${ }^{m}$ \\ Manuscripts}




\section{What human blood-brain barrier models can tell us about BBB function and drug discovery?}

Keywords: blood-brain barrier (BBB), human in vitro models, drug discovery, BBB function, stem cells. 


\begin{abstract}
Introduction. The human in vitro blood-brain barrier (BBB) models may offer an important tool to study BBB development, maintenance and regulation. However, our capacity to obtain information from these models is still limited in part because only in recent years (i) these models have been derived from non-brain cell sources (e.g. stem cells), (ii) microfluidic systems have been developed to recapitulate aspects of BBB physiology and (iii) new insights into the molecular and cellular mechanisms of BBB diseases (e.g. Huntington's, Allan-Herndon-Dudley Syndrome) have been described.
\end{abstract}

Area covered. This article reviews (i) technological advances (particularly in the last 3 years) in the derivation of human cells from the neurovascular unit using stem cells and the creation of personalized BBB models generated from patients with neurodegenerative diseases, as well as, (ii) the scientific advances generated from the in vitro BBB models regarding neuroinflammation, contribution of individual cells of the BBB for BBB function and disease, response to mechanical forces (ECs) and drug discovery, BBB permeability and modulation.

Expert opinion. The recent technological advances in the derivation of human cells from the neurovascular unit from stem cells as well as in the generation of BBB-on-a-chip that recapitulate in vitro part of the BBB physiology are significant to generate more robust BBB models; however, a considerable effort is still needed to validate the potential of these models to recapitulate the in vivo cellular and molecular mechanisms, in particular regarding BBB function in health and disease.

List of abbreviations: brain-like endothelial cells (BLECs); blood-brain barrier (BBB); endothelial cells (ECs); neurovascular unit (NVU); Allan-Herndon-Dudley syndrome (AHDS); Huntington's disease (HD); P-glycoprotein (Pgp); multidrug resistance protein (MRP-1); breast cancer resistance protein (BCRP); induced pluripotent stem cells (iPSCs); neural stem cells (NSCs); glial fibrillary acidic protein (GFAP); retinoic acid (RA); extracellular matrix (ECM); trans-endothelial electrical resistance (TEER); tumor necrosis factor-alpha (TNF- $\alpha$ ); granulocyte colony stimulating factor (GCSF); claudin 5 (CLDN5); peripheral blood mononuclear cells (PBMNCs); zonula occludens-1 (ZO1); von Willebrand factor (vWF); glucose transporter 1 (GLUT-1); L-type amino acid transporter 1 (LAT1); monocarboxylate transporter 1 (MCT1); chemokine (C-C motif) ligand 2 (CCL2).

\title{
1- Introduction
}


Drug development for the treatment of brain diseases requires the study of the effect of the drug in the BBB as well as its transport through the BBB. Typically, these tests are performed in small animals since they allow the characterization of the drug's pharmacodynamics and pharmacokinetics as well as the potential immune response elicited by drug. However, these tests are costly, time consuming and raise ethical issues due to animal use. In addition, due to the differences between the $\mathrm{BBB}$ in animals and humans in the expression of P-glycoprotein (Pgp), multidrug resistance-associated proteins, transporters and claudins as well as brain pharmacokinetics of Pgp substrates (reviewed in [1]), many successful drugs in pre-clinical models failed in the translation to humans. Computational (or "in silico") strategies have been proposed as a potential tool to predict BBB drug permeability; however, the insufficient data for modeling active transport processes hindered the general adoption of these methodologies [2]. Therefore, since the first isolation of brain capillaries almost 50 years ago [3], researchers have devoted considerable resources to generate human in vitro $\mathrm{BBB}$ models capable of mimicking the in vivo counterpart. The first human brain EC line (hCMEC/D3) was derived in 2005 [4] and human BBB models based on cells derived from human pluripotent stem cells [5], hematopoietic stem/progenitor cells [6] and circulating endothelial progenitor cells [7] have only been generated between 2012 and 2014. Therefore, the human in vitro BBB models have a relatively short history.

Human in vitro $\mathrm{BBB}$ models are very important models to study pathological and physiological mechanisms of the BBB and to identify formulations (e.g. drugs, nanocarriers) that are able to cross this biological barrier [8-11]. Several BBB models have been proposed based on static (e.g. transwell systems) and dynamic (e.g. BBB-on-a-chip) systems. In these systems, cells of the neurovascular unit (NVU) (e.g. ECs, astrocytes, pericytes, neurons, microglia, amongst others) have been derived/isolated from primary sources, immortalized cells, or stem cell derivatives. The advantages and limitations of these systems have been largely discussed in recent reviews and thus will not be covered here $[1,8,12]$. Human cells can be obtained from biopsies or autopsies of patients 
with brain diseases such as epilepsy, Alzheimer's disease (AD), brain tumors, among others. Unfortunately, the isolation process is costly and time consuming. Human cells of the NVU can be obtained from human immortalized cells; however, in general, the brain ECs suffer from high permeability and they do not offer a possibility for the generation of genetic disease BBB models. Finally, human cells of the NVU may be derived from human pluripotent stem cells [5] or human multipotent stem/progenitor cells [6,7]. To generate a reliable in vitro human BBB model one should generate cells that: (i) express brain EC markers including endothelial (VE-cadherin, vWF, CD31) and tight junction (claudin 1, claudin 3, claudin 5, occludin, ZO-1), (ii) display high junctional tightness as measured by TEER and paracellular permeability measurements (the in vivo TEER is estimated to be between 1000 and $2000 \Omega \mathrm{cm}^{2}$ in rat or frog brains [13,14]), (iii) express efflux transporters (including Pgp, BCRP, and MRP), solute carrier transporters (GLUT-1, LAT1, MCT1) and receptors (e.g. transferrin) (for all these proteins, the levels have been determined by mass spectrometry on brain ECs isolated from human individuals [1]), (iv) have low vesicular transport (i.e. downregulation of transcytosis markers such as caveolin-1 and plamalemma vesicle-associated protein (PLVAP) and upregulation of major facilitator superfamily domain containing 2a (Mfsd2a), a multitransmembrane lipid transporter [15]) and (v) responsiveness of the brain ECs to the regulation by NVU cells as well as pro-inflammatory signals.

In the last years, advances in BBB modeling have been mostly ascribed to the derivation of human NVU cells, in the in vitro recapitulation of the in vivo BBB extracellular matrix (ECM), and in the development of more advanced microfluidic systems able to recapitulate the BBB physiology (Fig. 1). Due to these advances, the first stem cell-based BBB models derived from genetic-driven diseases such as Huntington's disease and Allan-Herndon-Dudley Syndrome have been developed in $2017[16,17]$. Moreover, our understanding about the function, activity and regulation of the BBB in health and disease has improved. The in vitro BBB models allowed us to gather relevant information at cellular and molecular levels. The first part of this article reviews the technological advances in 
human BBB modeling, particularly in the last 3 years, and the second part reviews the biological information that has been generated using these models. Finally, the article discusses future directions in this research area.

\section{2- Recent advances in the development of human in vitro BBB models}

\section{1- Advances in the derivation of human NVU cells}

\subsection{1- Human brain-like endothelial cells (BLECs)}

In the last 5 years most of the progresses reported in the derivation of human BLECs have been achieved using iPSCs as cell source. Initial studies reported the derivation of human BLECs from iPSCs using a differentiation protocol that involved a co-culture of neural and endothelial progenitor cells $[5,18,19]$ (Fig. 2A). The differentiation protocol had several limitations including the fact that the differentiation media was not chemically defined and the signature and dynamic of the different subpopulations arising during the differentiation protocol was not well characterized. In the last years, progresses have been done in the derivation of human BLECs in a chemically defined media $[19,20]$ allowing researchers to investigate in more detail the mechanisms that specify hPSCs into BLECs. Several signaling pathways have been identified to play an important role either in the differentiation of iPSCs into endothelial progenitor cells as well as their specification into BLECs such as the canonical Wnt and retinoic acid (RA) pathways [5,18]. Developmental biology studies have shown that the Wnt signaling pathway controlled the specification of ECs into the brain subphenotype $[21,22]$ whereas the RA signaling was recently identified as critical for the induction of the BBB development $[18,23]$.

Progresses have been also done in the derivation of BLECs in chemical defined media using a two-step protocol comprising the differentiation into vascular progenitor cells followed by their differentiation into BLECs [20] (Fig. 2B). This protocol shed light into the developmental steps involved in the generation of ECs with brain sub-phenotype. Initially, hiPSCs were differentiated into 
mesoderm progenitor cells by the activation of the canonical Wnt signaling. These progenitor cells were characterized by the expression of vascular endothelial growth factor receptor 2. Subsequently, these vascular progenitor cells were differentiated into BLECs in culture medium containing RA. At the end of the differentiation process (day 8), the cells were cultured on top of human placenta-derived collagen IV/human plasma-derived fibronectin coated surface for 2 days for the generation of the BBB model.

The derivation of $\mathrm{BBB}$ models from iPSCs generated from patients with neurodegenerative diseases has been reported recently. BLECs have been derived from Huntington's disease (HD) [16] as well as from Allan-Herndon-Dudley syndrome (AHDS) iPSCs [17] using previously established differentiation protocols [5]. No differences in the percentage of BLECs obtained from HD and control iPSCs was observed. However, HD-BLECs showed increased migration compared to control BLECs and this difference could not be attributed to differences in BLEC proliferation. In addition, HD-BLECs formed a continuous cell monolayer showing alterations in the localization of CLDN5 at cell junctions, reduced trans-endothelial electrical resistance (TEER) values as compared to control BLECs and aberrant Pgp function (Fig. 3) suggesting that the BBB formed by HD-BLECs had increased paracellular permeability. Moreover, HD-BLECs transcriptome was distinct from control BLECs lending support to the notion that cellular and molecular differences between HD and controlderived cells play an important role in BBB function. Using this BBB model, the authors identified a small molecule WNT inhibitor, XAV939, that was able to recue some of the defects observed in the biological properties of HD-BLECs. Noteworthy, the derivation of BBB models from iPSCs derived from patients also requires the generation of isogenic cell lines (i.e., cells that have the same genetic background but without the genetic mutation responsible for the disease) [17,24]. These isogenic cell lines are critical to study the effect of the mutation in the developmental and functional properties of the BBB. 
Although the derivation of BLECs from iPSCs has been demonstrated in chemically defined conditions, further testing is needed to demonstrate their long-term stability and BBB properties. Some general properties of in vitro BBB models are presented in Table 1 . The in vitro BBB models generated from iPSC-derived BLECs have a higher TEER (between 1000 and $2000 \Omega \mathrm{cm}^{2}$; although unstable over time) than models generated by BLECs derived from adult human progenitor cells or immortalized human brain ECs [19,20]. Further analyses are required to verify the maintenance of the brain sub-phenotype of the ECs, in particular after long-term expansion (necessary to obtain sufficient number of cells for high-throughput screening, for example) as it has been done for other ECs [25]. In this case, the temporal modulation of certain signaling pathways might be required to maintain the stability of the phenotype [26]. Moreover, the co-culture of iPSC-derived BLECs with astrocytes and pericytes in a perfused three-dimensional network might also increase the stability of the derived cells since they showed paracellular permeability values close to the ones found in vivo [27]. Another aspect that requires further attention is the functional characterization of BLECs. In most studies, a restricted number of functional assays have been used to characterize BLECs (e.g. upregulation of intercellular adhesion molecule 1 expression after treatment with tumor necrosis factor $\alpha$, efflux transporter activities such as Pgp, MRP and BCRP, polarization of Pgp activity) [20] and therefore a more exhaustive functional characterization of transporters, receptors (e.g. transferrin, toll-like receptors, adenosine receptors), expression of chemokines, among other parameters, should be done.

\subsection{2- Human astrocytes, pericytes, neurons and microglia}

Besides human brain ECs, the inclusion of cells from the NVU (e.g. human astrocytes, neurons, microglia and pericytes) may help the development of more reliable in vitro BBB models $[1,6,8]$. These cells provide cues that are critical in the development, maintenance, and regulation of unique BBB properties. In some cases, they have been isolated from human autopsies/biopsies [28] 
while in other cases they have been generated from human hematopoietic progenitor cells [29] or hiPSCs [30]. In this last case, some studies have derived human brain ECs, astrocytes and neurons from the same iPSC line to generate isogenic in vitro BBB models formed by co-culture of the different cells [24]. It is important to note that these iPSC-based models create an interesting opportunity for personalized medicine.

Human astrocytes have been derived either from hiPSC-derived neural stem cells (NSCs) [30] or cell aggregates (EZ spheres) [24]. The NSCs were characterized by the expression of markers including transcription factors SOX1 and SOX2 as well as the intermediate filament protein NESTIN and the absence of pluripotency and astroglial markers [30]. The NSCs were then differentiated into astrocytes expressing the protein glial fibrillary acidic protein (GFAP). For the differentiation protocol comprising a cell aggregate step, iPSCs were initially differentiated as cell aggregates (EZ spheres) and subsequently, using astrocyte induction medium supplemented with RA, differentiated into astrospheres, a neural progenitor population [24]. Astrospheres were differentiated into astrocytes in culture medium supplemented with N2 ultimately yielding cells with glial morphology, expression of GFAP and S100 calcium binding protein (S100B), and absence of the expression of PAX- 6 or $\beta$ III tubulin.

Human neurons have been also derived from hiPSCs. In this case, at least two different differentiation protocols have been developed either with or without cell aggregates (EZ spheres). In one case, iPSCs were cultured in the presence of an inductive medium generating a mixture of neurons and astrocytes [31]. In the second case, iPSCs were differentiated into neurons from EZ-spheres [24] using basal media supplemented with B27 (without vitamin A). In both protocols [24,31], the neurons were characterized by the expression of $\beta$ III-TUBULIN, NCAM, NeuN, glutamate transporters VGLUT1, VGLUT2, synaptic proteins SYNAPTOTAGMIN and SYNAPTOPHYSIN and by the capacity to generate action potentials as demonstrated by patch-clamp techniques. These cells did not express GFAP, an astrocyte marker, or S100B, a mature glial-specific marker. 
Finally, human pericytes have been also derived from human iPSCs. In this case, iPSCs were differentiated into early vascular cells $\left(\mathrm{CD} 146^{+} \mathrm{CD} 105^{+} \mathrm{VECAD}^{+/-} \mathrm{PDGFR} \beta^{+/-}\right)$which were then specified into pericytes using a low concentration of vascular endothelial growth factor (VEGF) $[32,33]$. It remains to be determined whether these pericytes have brain-specific attributes.

\section{2- Advances in recapitulating the in vivo BBB ЕСМ}

The importance of ECM during iPSC differentiation into BLECs and then in the formation of a BBB monolayer is a topic that deserves further investigation. The remodeling of ECM during the induction of the $\mathrm{BBB}$ has been shown by developmental studies but its importance during the differentiation of iPSCs into BLECs has not been investigated. In contrast, the role of the ECM during the formation and maturation of the BBB has been in partially investigated. For example, it has been demonstrated that the basement membrane ECM is important for the barrier properties of BLECs [34], including the presence of collagen type IV, fibronectin and laminin. In addition, the impact of the ECM composition during the formation and maintenance of BBB using iPSC-derived BLECs has been investigated [35]. Cells cultured in chemically-crosslinked collagen I gels coated with a mixture of fibronectin and collagen IV enabled the formation of confluent EC monolayers ultimately yielding a BBB with the highest TEER value compared to controls [35].

The ECM is important not only due to the specific chemistry but also due to the topography and mechanical properties of its constituents. In most of the current in vitro BBB models, the brain ECs are cultured on transwell membrane inserts which have mechanical properties $(\approx 2 \mathrm{GPa})$ markedly different from the in vivo $\mathrm{BBB}$ ECM $(8-10 \mathrm{kPa})$ [36]. Recent studies have shown that 3D nanofibers matrices prepared by either poly(lactic-co-glycolic acid) (PLGA) (diameter of PLGA nanofibers: $800 \mathrm{~nm}$; Young's modulus: $\approx 54 \mathrm{MPa}$ ) or gelatin may be a better substrate for BBB formation and maintenance [36,37]. In this case, iPSC-derived BLECs as well as iPSC-derived astrocytes were able to migrate through the three-dimensional electrospun mesh and the reported 
TEER values of $\approx 180 \Omega \mathrm{cm}^{2}$ were closer to the in vivo counterpart. Moreover, a two-photon lithography technique has been used to develop a dynamic three-dimensional BBB model able to reproduce, at 1:1 scale, the capillaries of the neurovascular system [38]. The scaffold of the BBB model consisted of a porous tubular structure $(10 \mu \mathrm{m}$ in diameter $)$ in which brain ECs were deposited to form a three-dimensional tubular structure. Although the model was generated with mouse brain ECs, it is anticipated that the same microfabricated scaffold may be used with human brain ECs.

\section{3- Advances in BBB modeling}

In the last years, organ-on-chip have emerged as a promising study platform to unravel spatial and temporal dynamics of the biological barriers including the BBB $[12,39,40]$. BBB-on-a-chip are microfluidic devices in which cells of the NVU (e.g. brain ECs, astrocytes, neurons, pericytes, microglia) are cultured in a controlled microenvironment (e.g. perfusion with cell culture media in conditions that mimic in vivo fluid flow; adhesion to ECM components that exist in the basement membrane of the $\mathrm{BBB}$; cultured in substrates with a certain topography and geometry that mimics the curvature that the cells are exposed to in the in vivo $\mathrm{BBB}$ ) that recapitulates, at least in part, the in vivo BBB environment, and from which we can obtain biological information (through the use of sensors included in the microfluidic systems) [41]. Indeed, data collected from different studies has shown that these dynamic BBB models may offer an advantage to conventional Transwell systems for the study of immune cell migration through the BBB [29] as well as to study the neurovascular function and inflammatory processes [42]. In addition, they offer a more complex environment than dynamic in vitro BBB models established previously based on co-cultures of human microvascular ECs with human astrocytes $[43,44]$. For the generation of BBB-on-a-chip, human brain microvascular ECs [28], human brain ECs from human hematopoietic progenitor cells [29], iPSC-derived BLECs $[45,46]$ as well as primary cells from the NVU have been used. Both $2 \mathrm{D}[47,48]$ and $3 \mathrm{D}[42,49-53]$ models of BBB have been developed within microfluidic platforms. The 3D models recapitulate in 
vitro the $3 \mathrm{D}$ cellular organization existent in the in vivo $\mathrm{BBB}$ and are therefore preferred to study the activity of brain parenchyma including neuronal activity; however, the complexity of the model may not be desirable for certain applications such as high-throughput screening. Ten BBB-on-a-chip models (4 of which human BBB models) have been described until 2016 [41] and the number has increased to approximately 20 in the last 2-3 years.

The BBB-on-a-chip was very useful to obtain insights into the communication between the different cells comprising the NVU [28]. In addition, the BBB-on-a-chip models can monitor in real time biological/transport parameters associated with the BBB that are important for a better understanding of BBB physiology. The BBB-on-a-chip has sensors able to monitor in real time the TEER, the transport of molecules between the microfluidic chambers, the transmigration of neutrophils across the endothelial barrier in the presence of an inflammatory trigger, among other properties.

Currently, BBB-on-a-chip models have some limitations. An important limitation described in most BBB-on-a-chip studies is the fact that the flow shear stress used was lower than the physiological (10-20 dynes $\mathrm{cm}^{-2}$ in brain capillaries [54] versus below 10 dyne/ $\mathrm{cm}^{2}$ in BBB-on-achip $[28,42])$. In some cases, the low flow shear stress was motivated by economic reasons (i.e., cost associated to large volumes of cell culture media) [42]. Yet, it is known that flow shear stress is important to increase the contact area between cells and to make a robust BBB [45]. In contrast to other ECs, human brain ECs do not align in response to physiological shear stress and they do not show significant differences in cell average relatively to cells cultured under static conditions. With some exceptions [29], another limitation of the BBB-on-a-chip models is the fact that they did not explore the contribution of microglia and other cells from the immune system in the maintenance and activity of the BBB. Finally, BBB-on-a-chip models may not be ideal for high-throughput screening (HTS) endeavors because they require extensive optimization and the costs associated to cell culture media might be prohibitive. For HTS, the use of BBB spheroids, formed by a core of astrocytes and 
a surface layer of brain ECs and pericytes, displaying reproducible features and functions may be an alternative to BBB-on-a-chip models [55]. However, the low reproducibility in the generation of BBB spheroids might limit the readout of the screening.

\section{3- What have we learned from in vitro BBB models in terms of BBB biology and treatment?}

Despite the significant progresses made in BBB modelling during the last years, namely in our ability to recapitulate in the laboratory aspects of the human BBB biology, a very important question remains to be addressed: what have we learned in terms of BBB biology and treatment from these in vitro human BBB models? Below, we describe several areas in which the human in vitro BBB models have been useful to elucidate BBB biology, regulation and permeability (Fig. 4).

\section{1- Neuroinflammation}

Human in vitro BBB models have been very useful to demonstrate the regulatory mechanisms of BBB permeability in pathological conditions mediated by pro-inflammatory molecules such as tumor necrosis factor-alpha (TNF- $\alpha$ ) or chemokine (C-C motif) ligand 2 (CCL2) [56] and oxygen and glucose deprivation [57]. Pro-inflammatory molecules, present in the systemic circulation, have the capacity to induce the opening of the $\mathrm{BBB}$ and reduce the expression and activity of efflux transporters such as Pgp and BCRP [58]. The magnitude of this effect is likely different in humans versus other mammalians due to differences in the expression of adhesion molecules, such as ICAM-1 and VCAM-1, as well as transporters such as Pgp [1]. A 3D BBB model generated in a microfluidic chip highlighted the individual contributions of brain vasculature-associated cells to neuroinflammation, after exposure to TNF- $\alpha$ [42]. Co-cultures of human astrocytes or human pericytes with human brain ECs in the microfluidic chip led to enhanced secretion of granulocyte colony stimulating factor (G-CSF) and interleukin-6 after exposure to TNF- $\alpha$ when compared with brain ECs alone. Interestingly, an increase in G-CSF secretion was already observed in the co-culture 
of pericytes with brain ECs even without exposure to TNF- $\alpha$ (this was not the case in the co-culture of astrocytes with brain ECs).

Human in vitro models were also important to study the interaction of human monocytes with the brain ECs and the mechanism of BBB opening. The blockage of ERK1/2 pathway [59] or the activation of sphingosine-1-phosphate receptor [60] in brain ECs may reduce the capacity of monocytes to open the BBB and to cross it. In addition, the human BBB models have been useful to study the adhesion and migration of peripheral blood mononuclear cells (PBMNCs) across a monolayer of brain ECs in the context of pathologies such as multiple sclerosis [61]. For example, it has been shown that PBMNCs migration was dependent on the percentage of cells expressing PSGL1. Migration across the BBB of PBMNCs from patients with multiple sclerosis (having high number of $\mathrm{CD}^{+} \mathrm{T}$ lymphocytes expressing PSGL-1) was higher than PBMNCs from healthy individuals. The dynamics of $\mathrm{T}$ cell interaction with a human in vitro BBB model has been also investigated in a BBB-on-a-chip model [29]. Using this model, it was possible to demonstrate the polarization of $\mathrm{T}$ cells and the migration across the in vitro $\mathrm{BBB}$ model. Finally, human in vitro $\mathrm{BBB}$ models were paramount to study the interaction of pathogens with brain ECs, and these aspects have been reviewed elsewhere for an immortalized human brain EC [62]. It is expected that iPSC-derived BLECs may extend the biological information available because they will give information for each individual.

\section{2- BBB biology and maintenance}

The in vitro BBB models were very relevant to highlight the role of each cell type of the NVU in the induction and maintenance of the BBB. For example, studies with isogenic NVU cells (cells differentiated from the same iPSC donor) demonstrated that astrocytes, compared to neurons, induced a tighter BBB, as measured by TEER measurements, when co-cultured with brain ECs [24]. In addition, studies in a human in vitro BBB model composed of BLECs derived from human hematopoietic/progenitor cells indicated that pericytes were crucial to promote the formation of tight 
junctions and reduce paracellular permeability [6]. The importance of pericytes in the regulation of BBB properties has been further demonstrated by in vivo studies (for a review see ref. [63]). Moreover, a BBB-on-a-chip model containing several compartments, demonstrated: (i) intercellular communication, mediated by paracrine factors, between the brain ECs and the other cells at the NVU, and (ii) metabolic coupling between the vasculature and the brain parenchyma. The results supported the idea that endothelial and perivascular cells of the BBB secreted a higher number of different types of molecules than the neurons, at least in this particular milieu [28].

\section{3- BBB response to mechanical stress}

Important information has been collected about the activity of human brain ECs cultured under flow shear stress, such as their incapacity to align in response to flow shear stress $[45,64]$. In contrast to other ECs (e.g. human umbilical vein ECs), human brain ECs showed a random actin cytoskeleton in response to flow shear stress (up to 16 dyne $/ \mathrm{cm}^{2}$ ) [64]. The incapacity of cells to respond to flow might be due to a need of brain ECs to minimize paracellular transport into the brain which requires a reduction in the length of tight junctions per unit length of the capillary [65]. It is known that vascular endothelial (VE)-cadherin acts as a mechanosensory adaptor protein capable of transducing shear forces in ECs [66] which in turn influence the tight junction's assembly, such as occludin, by the engagement of a TiamI/RacI/phosphatase mechanism [67]. The enhanced localization of the tight-junctions to the cell-cell contacts significantly decrease the barrier permeability in brain ECs [67-69]. For example, the TEER value of a monolayer of immortalized human brain ECs (hCMEC/D3) in static conditions is in the order of $30-50 \Omega \mathrm{cm}^{2}$ while in dynamic conditions is in the order of $1000-1200 \Omega \mathrm{cm}^{2}$ [68]. It is interesting to note that the expression and localization of tight junctions such as claudin-5, occludin and ZO-1 in human iPSC-derived BLECs does not seem to be affected by flow shear stress suggesting that they might be established under static conditions [45]. Therefore, further studies are required to clarify whether iPSC-derived BLECs 
can recapitulate the effects of flow shear stress observed in somatic human brain ECs. Moreover, it is important to evaluate the effect of the flow in the permeability of the in vitro $\mathrm{BBB}$ models developed more recently using iPSC-derived BLECs and to evaluate the nitric oxide production, which is important in the stabilization of the BBB [70].

$\mathrm{BBB}$ models have been also instrumental to investigate the effect of the mechanical stretching in the regulation of BBB function [71]. Indeed, it is difficult to study in vivo the effect of mechanical stretching on solutes as well as to investigate alterations in blood flow induced by changes in the mechanical properties of the blood vessels. In vitro human BBB models provide a controlled environment to study this process. It is known that the blood vessel wall in AD patients is stiffer than in healthy individuals, and thus has low compliance to cyclic stretch [71]. Recent experimental data indicates that a pulsatile flow facilitates a retrograde transport of biomolecules along the basement membrane of brain ECs cultured in a microfluidic system. The retrograde transport is likely necessary for the transport of metabolic waste products from the BBB cells into the interstitial fluid reservoirs. This type of transport might be altered in less compliant BBB's, such as the one in AD patients, and thus might contribute for the BBB breakdown.

\section{4- Drug toxicity, permeability and regulation of the BBB}

Human in vitro BBB models generated from iPSCs [36], human hematopoietic stem cells [72,73] or the human EC line hCMEC/D3 [74] have been used to study drug toxicity, permeability, and regulation of the $\mathrm{BBB}$. The toxicity and permeability of drugs such as anticancer agents (e.g. paclitaxel and bortezomib for brain glioma) [36], the A $\beta$ peptide, a hallmark in AD [36], as well as BBB peptide shuttles [73] have been investigated. In some cases, the results demonstrated that the drugs had higher permeability in the human in vitro BBB models than in BBB models of other species [73]. A high-throughput screening has identified compounds that decreased in vitro BBB model permeability after activation by an AD peptide [74]. Although 7 drugs have been identified using a 
mouse in vitro $\mathrm{BBB}$ model, only 3 were active in the human in vitro BBB model. It is important to note that most of the transport studies reported so far with human in vitro BBB models have been validated with mouse $\mathrm{BBB}$ pharmacokinetics due to the scarce information available on human BBB pharmacokinetics $[5,27,31]$. Therefore, further efforts are necessary in the near future to determine the transport kinetics of drugs in human brain by techniques such as positron emission tomography (PET) as well as others.

The human in vitro BBB models were also important to evaluate the internalization and intracellular trafficking of nanoformulations [72,75,76]. For example, experimental results showed that the density of transferrin peptide on the surface of the nanoformulations correlated with the level of internalization as well as the intracellular trafficking (i.e., whether the formulation ended up in the lysosome or was transported by transcytosis). Moreover, the internalization mechanism (e.g. caveolar endocytosis, adsorptive mediated endocytosis and receptor-mediated endocytosis) of nanoparticles was influenced by their surface modification [76]. The human in vitro BBB models have been also important to investigate the effect of temperature in transient opening of the BBB [72]. Local heat $\left(10-15^{\circ} \mathrm{C}\right.$ above the physiological $\left.37^{\circ} \mathrm{C}\right)$ generated by nanoformulations was sufficient to open the $\mathrm{BBB}$, as evaluated by an increase in the paracellular permeability to Lucifer yellow and the disruption of the intercellular contacts between ECs [72].

The BBB models have been also important to highlight differences in the intracellular transport between species. The vesicular transport in brain ECs is lower than in peripheral ECs [77]. Recent work has demonstrated that transcytosis is inhibited in brain ECs and the up-regulation of transcytosis contributed for a leaky BBB without apparent disruption of tight junctions [78]. Proteins are transported through the $\mathrm{BBB}$ by receptors including insulin, transferrin and low-density lipoprotein receptors, being the kinetics likely different between species. In fact, the transcytosis kinetics of different antibodies against a human and a rat in vitro BBB model has been evaluated [31], 
being the permeability of an antibody raised against $C$. difficile toxin A (A20.1) 2-fold lower in the human BBB model as compared to the rat BBB model.

\section{4- Expert Opinion}

Our knowledge about the in vivo human BBB development, maintenance and function is still poor, and thus it is difficult to establish the full features of an ideal human BBB model. Some of the features have been reviewed recently [8]. So far, no in vitro BBB model reproduces all the features found in the in vivo $\mathrm{BBB}$; however, despite these limitations, the in vitro $\mathrm{BBB}$ models are a very useful tool to study BBB-related diseases, drug permeability, among others. An important point that deserves further consideration in BBB modeling is standardization, i.e., to create standards for quantitative evaluation of BBB function such as permeability and TEER, cells used for the creation of the models, level of shear stress, among others. Due to the recent advances in single cell analyses, gene editing systems, iPSC biology, microtechnologies, we anticipate rapid progresses in our understanding of the BBB biology and physiology in the near future.

The stem cell-based BBB models offer the possibility to study the BBB formation from a developmental perspective which might be desirable in the setting of specific diseases. For example, using these models, it will be possible to investigate which ECM components, signaling pathways, or the contribution of each NVU cell component in the formation of the BBB. In addition, it will be possible to study the kinetics of the specification of ECs into brain ECs. So far, the human BLECs derived from stem cells were derived based on the modulation of Wnt and RA signaling pathways. However, it is likely that other signaling pathways are important for the derivation of BLECs as well as for the generation and maintenance of the BBB. Single cell high-resolution gene expression analyses of mouse embryonic brain ECs showed that these cells have high abundance of Foxf2, Foxq1, Ppard and Zic3 brain endothelium-specific transcription factors [79]. Indeed, the expression of Foxf2 and Zic3 in human vein ECs yielded cells with brain endothelial features. The involvement 
of the transcription factor SOX17 seems also important to control BBB permeability through the modulation of canonical Wnt/ $\beta$-catenin signaling [80]. The human stem cell-based BBB models also offer a possibility to evaluate the permeability of the BBB to small molecules and/or biologicals, in the context of drug development. Indeed, some of the in vitro models have been used to predict central nervous system distribution of a small number of compounds in humans and thus, further testing is necessary to evaluate large number of compounds [6].

Although several BBB models have been developed to recapitulate in vitro the BBB conditions of several brain diseases such as glioblastoma (by co-culturing brain ECs with glioblastoma cell lines), AD (by using cells from rat and mouse models of AD), stroke (culturing the BBB model in ischemic conditions), among others, the generation of human genetic disease BBB models was only reported in 2017 [16,17]. The generation of disease BBB models was a significant achievement because it demonstrated the utility of these models to identify new disease mechanisms and potential therapies that otherwise would be difficult. For example, in the case of AHDS, the animal models available did not present the full phenotype typical of the disease in humans, such as, neurological or behavioral abnormalities [17]. It is important to highlight the importance of gene editing tools to validate the effect of a given mutation in the BBB model, in particular in isogenic lines that have the same genetic background of the cells used to generate the disease model.

The combination of iPSC-derived BLECs and microfluidic systems opens new possibilities for the creation of personalized BBB models. During the preparation of this manuscript, it has been demonstrated that iPSC-based BBB chips may be useful to predict inter-patient variability in BBB function [81]. For that, several iPSC-based chips containing iPSC-derived BLECs from different individuals have been used. In some of these studies, whole blood treated with anticoagulant has been perfused at a shear rate of $5 \mathrm{dyne} / \mathrm{cm}^{2}$. Future studies should further explore these iPSC-based BBB chips to study how individual variability can explain differences in patient response to drugs. 
Acknowledgments. This work was funded by FEDER through the Program COMPETE and by Portuguese fund through FCT in context of the projects "AGING-MODEL" (Ref. POCI-01-0145FEDER-029229) and "Unraveling the Rules of Passive Permeation Through the Blood-Brain Barrier" (Ref: PTDC/DTP-FTO/2784/2014), as well as the European project ERAatUC (ref. 669088). LF would like to thank Dr. Hugo Fernandes for the critical reading of the manuscript.

Conflict of interest. The authors have no conflict of interest to disclose.

\section{References}

1. Aday S, Cecchelli R, Hallier-Vanuxeem D, Dehouck MP, Ferreira L. Stem Cell-Based Human Blood-Brain Barrier Models for Drug Discovery and Delivery. Trends Biotechnol, 34(5), 382-393 (2016).

2. Clark DE. In silico prediction of blood-brain barrier permeation. Drug Discov Today, 8(20), 927-933 (2003).

3. Joo F, Karnushina I. A procedure for the isolation of capillaries from rat brain. Cytobios, 8(29), 41-48 (1973).

4. Weksler BB, Subileau EA, Perriere N et al. Blood-brain barrier-specific properties of a human adult brain endothelial cell line. FASEB J, 19(13), 1872-1874 (2005).

5. Lippmann ES, Azarin SM, Kay JE et al. Derivation of blood-brain barrier endothelial cells from human pluripotent stem cells. Nat Biotechnol, 30(8), 783-791 (2012).

6. Cecchelli R, Aday S, Sevin E et al. A stable and reproducible human blood-brain barrier model derived from hematopoietic stem cells. PLoS One, 9(6), e99733 (2014).

7. Boyer-Di Ponio J, El-Ayoubi F, Glacial F et al. Instruction of circulating endothelial progenitors in vitro towards specialized blood-brain barrier and arterial phenotypes. PLoS One, 9(1), e84179 (2014).

8. Helms HC, Abbott NJ, Burek M et al. In vitro models of the blood-brain barrier: An overview of commonly used brain endothelial cell culture models and guidelines for their use. J Cereb Blood Flow Metab, 36(5), 862-890 (2016).

9. Banks WA. From blood-brain barrier to blood-brain interface: new opportunities for CNS drug delivery. Nat Rev Drug Discov, 15(4), 275-292 (2016).

10. Saraiva C, Praca C, Ferreira R, Santos T, Ferreira L, Bernardino L. Nanoparticle-mediated brain drug delivery: Overcoming blood-brain barrier to treat neurodegenerative diseases. J Control Release, 235, 34-47 (2016).

11. Gastfriend BD, Palecek SP, Shusta EV. Modeling the blood-brain barrier: Beyond the endothelial cells. Curr Opin Biomed Eng, 5, 6-12 (2018).

12. Kaisar MA, Sajja RK, Prasad S, Abhyankar VV, Liles T, Cucullo L. New experimental models of the blood-brain barrier for CNS drug discovery. Expert Opin Drug Discov, 12(1), 89-103 (2017). 
13. Crone C, Olesen SP. Electrical resistance of brain microvascular endothelium. Brain Res, 241(1), 49-55 (1982).

14. Butt AM, Jones HC, Abbott NJ. Electrical resistance across the blood-brain barrier in anaesthetized rats: a developmental study. J Physiol, 429, 47-62 (1990).

15. Andreone BJ, Chow BW, Tata A et al. Blood-Brain Barrier Permeability Is Regulated by Lipid Transport-Dependent Suppression of Caveolae-Mediated Transcytosis. Neuron, 94(3), 581-594 e585 (2017).

16. Lim RG, Quan C, Reyes-Ortiz AM et al. Huntington's Disease iPSC-Derived Brain Microvascular Endothelial Cells Reveal WNT-Mediated Angiogenic and Blood-Brain Barrier Deficits. Cell Rep, 19(7), 1365-1377 (2017).

17. Vatine GD, Al-Ahmad A, Barriga BK et al. Modeling Psychomotor Retardation using iPSCs from MCT8-Deficient Patients Indicates a Prominent Role for the Blood-Brain Barrier. Cell Stem Cell, 20(6), 831-843 e835 (2017).

18. Lippmann ES, Al-Ahmad A, Azarin SM, Palecek SP, Shusta EV. A retinoic acid-enhanced, multicellular human blood-brain barrier model derived from stem cell sources. Sci Rep, 4, 4160 (2014).

19. Hollmann EK, Bailey AK, Potharazu AV, Neely MD, Bowman AB, Lippmann ES. Accelerated differentiation of human induced pluripotent stem cells to blood-brain barrier endothelial cells. Fluids Barriers CNS, 14(1), 9 (2017).

20. Qian TC, Maguire SE, Canfield SG et al. Directed differentiation of human pluripotent stem cells to blood-brain barrier endothelial cells. Sci Adv, 3(11) (2017).

21. Liebner S, Corada M, Bangsow T et al. Wnt/beta-catenin signaling controls development of the blood-brain barrier. J Cell Biol, 183(3), 409-417 (2008).

22. Stenman JM, Rajagopal J, Carroll TJ, Ishibashi M, McMahon J, McMahon AP. Canonical Wnt Signaling Regulates Organ-Specific Assembly and Differentiation of CNS Vasculature. Science, 322(5905), 1247-1250 (2008).

23. Mizee MR, Wooldrik D, Lakeman KAM et al. Retinoic Acid Induces Blood-Brain Barrier Development. J Neurosci, 33(4), 1660-1671 (2013).

24. Canfield SG, Stebbins MJ, Morales BS et al. An isogenic blood-brain barrier model comprising brain endothelial cells, astrocytes, and neurons derived from human induced pluripotent stem cells. J Neurochem, 140(6), 874-888 (2017).

25. Rosa S, Praca C, Pitrez PR et al. Functional characterization of iPSC-derived arterial- and venous-like endothelial cells. Sci Rep, 9(1), 3826 (2019).

26. James D, Nam HS, Seandel M et al. Expansion and maintenance of human embryonic stem cell-derived endothelial cells by TGFbeta inhibition is Id1 dependent. Nat Biotechnol, 28(2), 161-166 (2010).

27. Campisi M, Shin Y, Osaki T, Hajal C, Chiono V, Kamm RD. 3D self-organized microvascular model of the human blood-brain barrier with endothelial cells, pericytes and astrocytes. Biomaterials, 180, 117-129 (2018).

28. Maoz BM, Herland A, FitzGerald EA et al. A linked organ-on-chip model of the human neurovascular unit reveals the metabolic coupling of endothelial and neuronal cells. Nat Biotechnol, 36(9), 865-+ (2018).

29. Mossu A, Rosito M, Khire T et al. A silicon nanomembrane platform for the visualization of immune cell trafficking across the human blood-brain barrier under flow. J Cereb Blood Flow Metab, 271678X18820584 (2018).

30. Appelt-Menzel A, Cubukova A, Gunther K et al. Establishment of a Human Blood-Brain Barrier Co-culture Model Mimicking the Neurovascular Unit Using Induced Pluri- and Multipotent Stem Cells. Stem Cell Reports, 8(4), 894-906 (2017). 
31. Ribecco-Lutkiewicz M, Sodja C, Haukenfrers J et al. A novel human induced pluripotent stem cell blood-brain barrier model: Applicability to study antibody-triggered receptor-mediated transcytosis. Sci Rep, 8(1), 1873 (2018).

32. Kusuma S, Shen YI, Hanjaya-Putra D, Mali P, Cheng L, Gerecht S. Self-organized vascular networks from human pluripotent stem cells in a synthetic matrix. Proc Natl Acad Sci US A, 110(31), 12601-12606 (2013).

33. Orlova VV, Drabsch Y, Freund C et al. Functionality of endothelial cells and pericytes from human pluripotent stem cells demonstrated in cultured vascular plexus and zebrafish xenografts. Arterioscler Thromb Vasc Biol, 34(1), 177-186 (2014).

34. Tilling T, Engelbertz C, Decker S, Korte D, Huwel S, Galla HJ. Expression and adhesive properties of basement membrane proteins in cerebral capillary endothelial cell cultures. Cell Tissue Res, 310(1), 19-29 (2002).

35. Katt ME, Linville RM, Mayo LN, Xu ZS, Searson PC. Functional brain-specific microvessels from iPSC-derived human brain microvascular endothelial cells: the role of matrix composition on monolayer formation. Fluids Barriers CNS, 15(1), 7 (2018).

36. Qi DJ, Wu SH, Lin HS et al. Establishment of a Human iPSC- and Nanofiber-Based Microphysiological Blood-Brain Barrier System. Acs Appl Mater Inter, 10(26), 21825-21835 (2018). 37. Bischel LL, Coneski PN, Lundin JG et al. Electrospun gelatin biopapers as substrate for in vitro bilayer models of blood-brain barrier tissue. J Biomed Mater Res A, 104(4), 901-909 (2016).

38. Marino A, Tricinci O, Battaglini M et al. A 3D Real-Scale, Biomimetic, and Biohybrid Model of the Blood-Brain Barrier Fabricated through Two-Photon Lithography. Small, 14(6) (2018).

39. Sackmann EK, Fulton AL, Beebe DJ. The present and future role of microfluidics in biomedical research. Nature, 507(7491), 181-189 (2014).

40. Bhatia SN, Ingber DE. Microfluidic organs-on-chips. Nat Biotechnol, 32(8), 760-772 (2014). 41. van der Helm MW, van der Meer AD, Eijkel JC, van den Berg A, Segerink LI. Microfluidic organ-on-chip technology for blood-brain barrier research. Tissue Barriers, 4(1), e1142493 (2016).

42. Herland A, van der Meer AD, FitzGerald EA, Park TE, Sleeboom JJ, Ingber DE. Distinct Contributions of Astrocytes and Pericytes to Neuroinflammation Identified in a 3D Human BloodBrain Barrier on a Chip. PLoS One, 11(3), e0150360 (2016).

43. Cucullo L, Marchi N, Hossain M, Janigro D. A dynamic in vitro BBB model for the study of immune cell trafficking into the central nervous system. J Cereb Blood Flow Metab, 31(2), 767-777 (2011).

44. Cucullo L, Hossain M, Rapp E, Manders T, Marchi N, Janigro D. Development of a humanized in vitro blood-brain barrier model to screen for brain penetration of antiepileptic drugs. Epilepsia, 48(3), 505-516 (2007).

45. DeStefano JG, Xu ZS, Williams AJ, Yimam N, Searson PC. Effect of shear stress on iPSCderived human brain microvascular endothelial cells (dhBMECs). Fluids Barriers CNS, 14(1), 20 (2017).

46. Wang YI, Abaci HE, Shuler ML. Microfluidic blood-brain barrier model provides in vivolike barrier properties for drug permeability screening. Biotechnol Bioeng, 114(1), 184-194 (2017).

47. Prabhakarpandian B, Shen MC, Nichols JB et al. SyM-BBB: a microfluidic Blood Brain Barrier model. Lab Chip, 13(6), 1093-1101 (2013).

48. Achyuta AK, Conway AJ, Crouse RB et al. A modular approach to create a neurovascular unit-on-a-chip. Lab Chip, 13(4), 542-553 (2013).

49. Urich E, Patsch C, Aigner S, Graf M, Iacone R, Freskgard PO. Multicellular self-assembled spheroidal model of the blood brain barrier. Sci Rep, 3, 1500 (2013).

50. Wang JD, Khafagy el S, Khanafer K, Takayama S, ElSayed ME. Organization of Endothelial Cells, Pericytes, and Astrocytes into a 3D Microfluidic in Vitro Model of the Blood-Brain Barrier. Mol Pharm, 13(3), 895-906 (2016). 
51. Brown JA, Pensabene V, Markov DA et al. Recreating blood-brain barrier physiology and structure on chip: A novel neurovascular microfluidic bioreactor. Biomicrofluidics, 9(5), 054124 (2015).

52. Adriani G, Ma D, Pavesi A, Kamm RD, Goh EL. A 3D neurovascular microfluidic model consisting of neurons, astrocytes and cerebral endothelial cells as a blood-brain barrier. Lab Chip, 17(3), 448-459 (2017).

53. Bang S, Lee SR, Ko J et al. A Low Permeability Microfluidic Blood-Brain Barrier Platform with Direct Contact between Perfusable Vascular Network and Astrocytes. Sci Rep, 7(1), 8083 (2017).

54. Wong AD, Ye M, Levy AF, Rothstein JD, Bergles DE, Searson PC. The blood-brain barrier: an engineering perspective. Front Neuroeng, 6, 7 (2013).

55. Cho CF, Wolfe JM, Fadzen CM et al. Blood-brain-barrier spheroids as an in vitro screening platform for brain-penetrating agents. Nat Commun, 8, 15623 (2017).

56. Lopez-Ramirez MA, Fischer R, Torres-Badillo CC et al. Role of caspases in cytokine-induced barrier breakdown in human brain endothelial cells. J Immunol, 189(6), 3130-3139 (2012).

57. Cowan KM, Easton AS. Neutrophils block permeability increases induced by oxygen glucose deprivation in a culture model of the human blood-brain barrier. Brain Res, 1332, 20-31 (2010).

58. Poller B, Drewe J, Krahenbuhl S, Huwyler J, Gutmann H. Regulation of BCRP (ABCG2) and P-glycoprotein (ABCB1) by cytokines in a model of the human blood-brain barrier. Cell Mol Neurobiol, 30(1), 63-70 (2010).

59. Reijerkerk A, Kooij G, van der Pol SM et al. Tissue-type plasminogen activator is a regulator of monocyte diapedesis through the brain endothelial barrier. J Immunol, 181(5), 3567-3574 (2008). 60. van Doorn R, Lopes Pinheiro MA, Kooij G et al. Sphingosine 1-phosphate receptor 5 mediates the immune quiescence of the human brain endothelial barrier. J Neuroinflammation, 9, 133 (2012).

61. Bahbouhi B, Berthelot L, Pettre S et al. Peripheral blood CD4+ T lymphocytes from multiple sclerosis patients are characterized by higher PSGL-1 expression and transmigration capacity across a human blood-brain barrier-derived endothelial cell line. J Leukoc Biol, 86(5), 1049-1063 (2009).

62. Weksler B, Romero IA, Couraud PO. The hCMEC/D3 cell line as a model of the human blood brain barrier. Fluids Barriers CNS, 10(1), 16 (2013).

63. Sweeney MD, Ayyadurai S, Zlokovic BV. Pericytes of the neurovascular unit: key functions and signaling pathways. Nat Neurosci, 19(6), 771-783 (2016).

64. Reinitz A, DeStefano J, Ye M, Wong AD, Searson PC. Human brain microvascular endothelial cells resist elongation due to shear stress. Microvasc Res, 99, 8-18 (2015).

65. Ye M, Sanchez HM, Hultz M et al. Brain microvascular endothelial cells resist elongation due to curvature and shear stress. Sci Rep, 4, 4681 (2014).

66. Tzima E, Irani-Tehrani M, Kiosses WB et al. A mechanosensory complex that mediates the endothelial cell response to fluid shear stress. Nature, 437(7057), 426-431 (2005).

67. Walsh TG, Murphy RP, Fitzpatrick P et al. Stabilization of brain microvascular endothelial barrier function by shear stress involves VE-cadherin signaling leading to modulation of pTyroccludin levels. J Cell Physiol, 226(11), 3053-3063 (2011).

68. Poller B, Gutmann H, Krahenbuhl S et al. The human brain endothelial cell line hCMEC/D3 as a human blood-brain barrier model for drug transport studies. J Neurochem, 107(5), 1358-1368 (2008).

69. Griep LM, Wolbers F, de Wagenaar B et al. BBB on chip: microfluidic platform to mechanically and biochemically modulate blood-brain barrier function. Biomed Microdevices, 15(1), 145-150 (2013).

70. Krizanac-Bengez L, Kapural M, Parkinson F et al. Effects of transient loss of shear stress on blood-brain barrier endothelium: role of nitric oxide and IL-6. Brain Res, 977(2), 239-246 (2003). 
71. Partyka PP, Godsey GA, Galie JR et al. Mechanical stress regulates transport in a compliant 3D model of the blood-brain barrier. Biomaterials, 115, 30-39 (2017).

72. Praca $\mathrm{C}$, Rai A, Santos $\mathrm{T}$ et al. A nanoformulation for the preferential accumulation in adult neurogenic niches. J Control Release, 284, 57-72 (2018).

73. Oller-Salvia B, Sanchez-Navarro M, Ciudad S et al. MiniAp-4: A Venom-Inspired Peptidomimetic for Brain Delivery. Angew Chem Int Ed Engl, 55(2), 572-575 (2016).

74. Qosa H, Mohamed LA, Al Rihani SB et al. High-Throughput Screening for Identification of Blood-Brain Barrier Integrity Enhancers: A Drug Repurposing Opportunity to Rectify Vascular Amyloid Toxicity. J Alzheimers Dis, 53(4), 1499-1516 (2016).

75. Ye D, Raghnaill MN, Bramini $\mathrm{M}$ et al. Nanoparticle accumulation and transcytosis in brain endothelial cell layers. Nanoscale, 5(22), 11153-11165 (2013).

76. Georgieva JV, Kalicharan D, Couraud PO et al. Surface characteristics of nanoparticles determine their intracellular fate in and processing by human blood-brain barrier endothelial cells in vitro. Mol Ther, 19(2), 318-325 (2011).

77. Villasenor R, Lampe J, Schwaninger M, Collin L. Intracellular transport and regulation of transcytosis across the blood-brain barrier. Cell Mol Life Sci, 76(6), 1081-1092 (2019).

78. Chow BW, Gu C. Gradual Suppression of Transcytosis Governs Functional Blood-Retinal Barrier Formation. Neuron, 93(6), 1325-1333 e1323 (2017).

79. Hupe M, Li MX, Kneitz S et al. Gene expression profiles of brain endothelial cells during embryonic development at bulk and single-cell levels. Sci Signal, 10(487) (2017).

80. Corada M, Orsenigo F, Bhat GP et al. Fine-Tuning of Sox 17 and Canonical Wnt Coordinates the Permeability Properties of the Blood-Brain Barrier. Circ Res, 124(4), 511-525 (2019).

81. Vatine GD, Barrile R, Workman MJ et al. Human iPSC-Derived Blood-Brain Barrier Chips Enable Disease Modeling and Personalized Medicine Applications. Cell Stem Cell, 24(6), 995-1005 e1006 (2019).

82. Baeten KM, Akassoglou K. Extracellular matrix and matrix receptors in blood-brain barrier formation and stroke. Dev Neurobiol, 71(11), 1018-1039 (2011).

83. van Dommelen JA, van der Sande TP, Hrapko M, Peters GW. Mechanical properties of brain tissue by indentation: interregional variation. J Mech Behav Biomed Mater, 3(2), 158-166 (2010).

Papers of special note have been highlighted as either of interest $\left(^{*}\right)$ or of considerable interest $\left({ }^{* *}\right)$ to readers.

*Ref. 4: Development and characterization of the most popular immortalized human brain EC line

\section{**Ref. 5: First human iPSC-derived BLECs}

*Ref. 6: First correlation between human in vitro and in vivo pharmacokinetic data

*Ref. 16 and Ref. 17: One of the first genetic disease BBB models derived from iPSCs

**Ref. 20: First human iPSC-derived BLECs in chemically defined conditions using defined vascular progenitor cells

**Ref. 28: Three-dimensional BBB-on-a-chip 


\begin{abstract}
**Ref. 72: Use of a human in vitro BBB model to screen nanoparticle formulations
**Ref. 81: Personalized BBB model
\end{abstract}

\title{
CAPTIONS
}

Figure 1- Recent advances on human in vitro BBB models. (i) Advances in replicating in vitro the BBB extracellular matrix including the topography, composition as well as the stiffness. For twodimensional $\mathrm{BBB}$ models, a mixture of collagen IV and fibronectin [5,20,28], or only Matrigel (primarily consisting in laminin, collagen IV and enactin) [6] have been used very often as ECM for the generation of BBB models. This is because mature brain ECs express several laminin-binding receptors, collagen IV and vitronectin receptors [82]. Indeed, the basement membrane of brain ECs is composed by mainly laminin, collagen IV, fibronectin and enactin. For three-dimensional BBB models, fibrin gel [27] and collagen type I [42] have been used. The ECM of these three-dimensional BBB models have similar mechanical properties of in vivo brain ECM (approximately $1 \mathrm{kPa}[83]$ ). Progresses have been done also in the reproduction of in vivo topography [36] and curvature [65] which have been transferred to culture substrates. (ii) Advances in the derivation of human cells of the NVU such as brain ECs, pericytes, astrocytes, neurons and microglia cells. Most of the progresses have been done in the derivation of human brain ECs from stem cells that have junctional tightness, expression of transporters and receptors as well as similar biological responses to stimuli as in vivo brain ECs [5-7]. In addition, the first disease BBB models based on stem cells have been derived [16,17]. (iii) Advances in exposing the brain ECs to physiological mechanical stress such as flow shear stress and mechanical stretching. (iv) Advances in BBB modeling. Most of the progresses have been done in the use of microfluidic systems to reproduce in vitro the $\mathrm{BBB}$ microenvironment $[28,46]$. Significant progresses have been done in the generation of 3D BBB models which have the advantage to reproduce better the mechanical properties of the basement membrane of brain ECs and facilitate their assembly $[27,42,52]$. 
Figure 2- Advances in the differentiation protocols of iPSCs into BLECs. (A) First line of differentiation protocol. The iPSCs were cultured in unconditioned medium for 5-7 days followed by their culture in defined endothelial cell medium for 2-5 days, and finally sub-cultured in a transwell system coated with a mixture of collagen IV and fibronectin. (B) Second line of differentiation protocol. The iPSCs were differentiated for $24 \mathrm{~h}$ in chemically defined medium supplemented with Wnt agonist (CHIR) followed by their differentiation into mesoderm and endothelial progenitor cells in medium without the agonist. At day 6, cells were cultured in the presence of medium supplemented with B27, RA and bFGF for 2 days. Finally, cells were cultured for 2 days in a transwell coated with a mixture of collagen IV and fibronectin.

Figure 3- In vitro disease BBB model generated from iPSCs derived from Huntington's disease (HD) patients. The in vitro HD model showed altered tight junctions (claudin 5 was localized both at junctions and intracellularly) and increased paracellular permeability than control BBB model. The BBB model showed also higher drug efflux (e.g. lipophilic drugs) due to an impaired function of Pgp. Moreover, the HD BBB model showed enhanced transcytosis due to a high expression of caveolin-1 in brain endothelial cells.

Figure 4- Scientific knowledge that has been collected from human in vitro BBB models. (A) Neuroinflammation: new insights have been collected about the dynamics of $\mathrm{T}$ cell migration across the BBB as well as the response of individual cells of the NVU to inflammation. (B) BBB biology: (B.1) new information has been collected about the paracrine signaling between cells of the NVU, specifically the paracrine signals secreted by astrocytes lead to a BBB with higher TEER and lower paracellular permeability than the factors secreted by neurons (see text); (B.2) new insights about the response of human $\mathrm{BBB}$ to mechanical stress including alignment, proliferation and migration as well 
as the permeability of the BBB to the temperature have been collected. (D) Identification of drugs regulating the $\mathrm{BBB}$ as well as formulations able to cross the $\mathrm{BBB}$ (see text). 


\section{Article highlights box}

- Despite the limitations of human in vitro BBB models to reproduce the in vivo complexity and activity of the $\mathrm{BBB}$, they are useful tools to study $\mathrm{BBB}$ development, $\mathrm{BBB}$ regulation in health and pathologic settings, and BBB transport activity.

- Stem cell-based BBB models offer the possibility to generate personalized BBB models to better understand $\mathrm{BBB}$ heterogeneity between individuals and for the identification of drugs and their concentrations to regulate and to cross the BBB.

- The generation of BBB models from iPSCs generated from individuals having neurodegenerative diseases open new opportunities to understand and treat BBB in a disease setting, in particular, in the context of rare diseases.

- Recent advances in the human in vitro models have been done, specifically in the derivation of human neurovascular unit cells from stem cells, in recapitulating in vivo BBB extracellular matrix and in the BBB modeling, particularly in the BBB-on-a-chips.

- The human in vitro BBB models are useful to elucidate neuroinflammation, BBB biology and maintenance, BBB response to mechanical stress, as well as to evaluate drug toxicity, permeability and regulation of the BBB. 
Table 1- Phenotypic and functional characteristics of human in vitro BBB models.

\begin{tabular}{|c|c|c|c|c|c|}
\hline Model & $\begin{array}{l}\text { Paracellular } \\
\text { permeability }\end{array}$ & $\begin{array}{l}\text { Pgp, BCRP } \\
\text { and MRP1 } \\
\text { activity } \\
\end{array}$ & $\begin{array}{l}\text { TEER } \\
\left(\Omega \mathrm{cm}^{2}\right)\end{array}$ & Tight junctions & $\begin{array}{l}\text { Vascular } \\
\text { inflammation }\end{array}$ \\
\hline $\begin{array}{l}\text { Static, } \\
\text { immortalized } \\
\text { brain } \\
\text { endothelial cells } \\
\text { hCMEC/D3[4] }\end{array}$ & $\begin{array}{l}\text { Dextran } 4 \mathrm{kDa}: 0.3 \times 10^{-3} \\
\mathrm{~cm} / \mathrm{min} \\
\text { Dextran } 70 \mathrm{kDa}: 0.01 \times 10^{-3} \\
\mathrm{~cm} / \mathrm{min}\end{array}$ & Yes & $30-40$ & $\begin{array}{l}\text { Expression of } \\
\text { claudin-5; } \\
\text { claudin-3 and } \\
\text { occludin were } \\
\text { not consistently } \\
\text { detected at the } \\
\text { cell-cell contacts }\end{array}$ & $\begin{array}{l}\text { Up-regulation of } \\
\text { ICAM-1 and } \\
\text { VCAM-1 after } \\
\text { treatment with } \\
\text { inflammatory } \\
\text { cytokines }\end{array}$ \\
\hline $\begin{array}{l}\text { Static, } \\
\text { circulating } \\
\text { endothelial } \\
\text { progenitor- } \\
\text { derived } \\
\text { BLECs[7] }\end{array}$ & $\begin{array}{l}\text { Lucifer yellow: } 1.2 \times 10^{-3} \\
\mathrm{~cm} / \mathrm{min}\end{array}$ & Yes for Pgp & $\sim 60$ & $\begin{array}{l}\text { Expression of } \\
\text { occludin, } \\
\text { claudin-5, } \\
\text { claudin- } 3 \text { and } \\
\text { ZO-1 }\end{array}$ & NA \\
\hline $\begin{array}{l}\text { Static, } \\
\text { hematopoietic } \\
\text { stem/progenitor- } \\
\text { derived } \\
\text { BLECs[6] }\end{array}$ & $\begin{array}{l}\text { Lucifer yellow: } 0.6 \times 10^{-3} \\
\mathrm{~cm} / \mathrm{min}\end{array}$ & Yes for Pgp & 165 & $\begin{array}{l}\text { Expression of } \\
\text { occludin, } \\
\text { claudin-5, } \\
\text { claudin-1 and } \\
\text { ZO-1 }\end{array}$ & $\begin{array}{l}\text { Up-regulation of } \\
\text { ICAM-1 and } \\
\text { VCAM-1 after } \\
\text { treatment with } \\
\text { inflammatory } \\
\text { cytokines }\end{array}$ \\
\hline $\begin{array}{l}\text { Static, iPSC- } \\
\text { derived } \\
\text { BLECs[18] }\end{array}$ & NA & Yes & $>2000$ & $\begin{array}{l}\text { Expression of } \\
\text { occludin, ZO-1 } \\
\text { and claudin-5; } \\
\text { claudin-1 and } \\
\text { claudin-3 were } \\
\text { not evaluated }\end{array}$ & $\begin{array}{l}\text { Upregulation of } \\
\text { ICAM-1 after } \\
\text { treatment with } \\
\text { inflammatory } \\
\text { cytokines; } \\
\text { VCAM-1 was } \\
\text { not tested }\end{array}$ \\
\hline $\begin{array}{l}\text { Static, iPSC- } \\
\text { derived } \\
\text { BLECs[20] }\end{array}$ & Sucrose: $5 \times 10^{-7} \mathrm{~cm} / \mathrm{s}$ & Yes & $>2000$ & $\begin{array}{l}\text { Expression of } \\
\text { occludin, ZO-1 } \\
\text { and claudin-5; } \\
\text { claudin-1 and } \\
\text { claudin-3 were } \\
\text { not evaluated }\end{array}$ & $\mathrm{NA}$ \\
\hline $\begin{array}{l}\text { Static, HD } \\
\text { iPSC-derived } \\
\text { BLECs[16] }\end{array}$ & NA & $\begin{array}{l}\text { Altered Pgp } \\
\text { activity; } \\
\text { BCRP and } \\
\text { MRP1 activity } \\
\text { not tested }\end{array}$ & $>2000$ & $\begin{array}{l}\text { Expression of } \\
\text { occludin, ZO-1, } \\
\text { claudin-5, } \\
\text { claudin-3 and } \\
\text { claudin-1 }\end{array}$ & NA \\
\hline $\begin{array}{lr}\text { Dynamic, } & \text { 3D- } \\
\text { human } & \text { BBB } \\
\text { model with cells } \\
\text { derived from } \\
\text { iPSCs[27] }\end{array}$ & $\begin{array}{l}\text { Dextran } 10 \mathrm{kDa}: 3 \times 10^{-7} \\
\mathrm{~cm} / \mathrm{s} \\
\text { Dextran } 40 \mathrm{kDa}: 0.89 \times 10^{-7} \\
\mathrm{~cm} / \mathrm{s}\end{array}$ & $\begin{array}{l}\text { Expression } \\
\text { but not } \\
\text { activity } \\
\text { analyses of } \\
\text { Pgp, BCRP } \\
\text { and MRP1 }\end{array}$ & NA & $\begin{array}{l}\text { Expression of } \\
\mathrm{ZO}-1 \text {, occludin, } \\
\text { and claudin-5 }\end{array}$ & NA \\
\hline
\end{tabular}



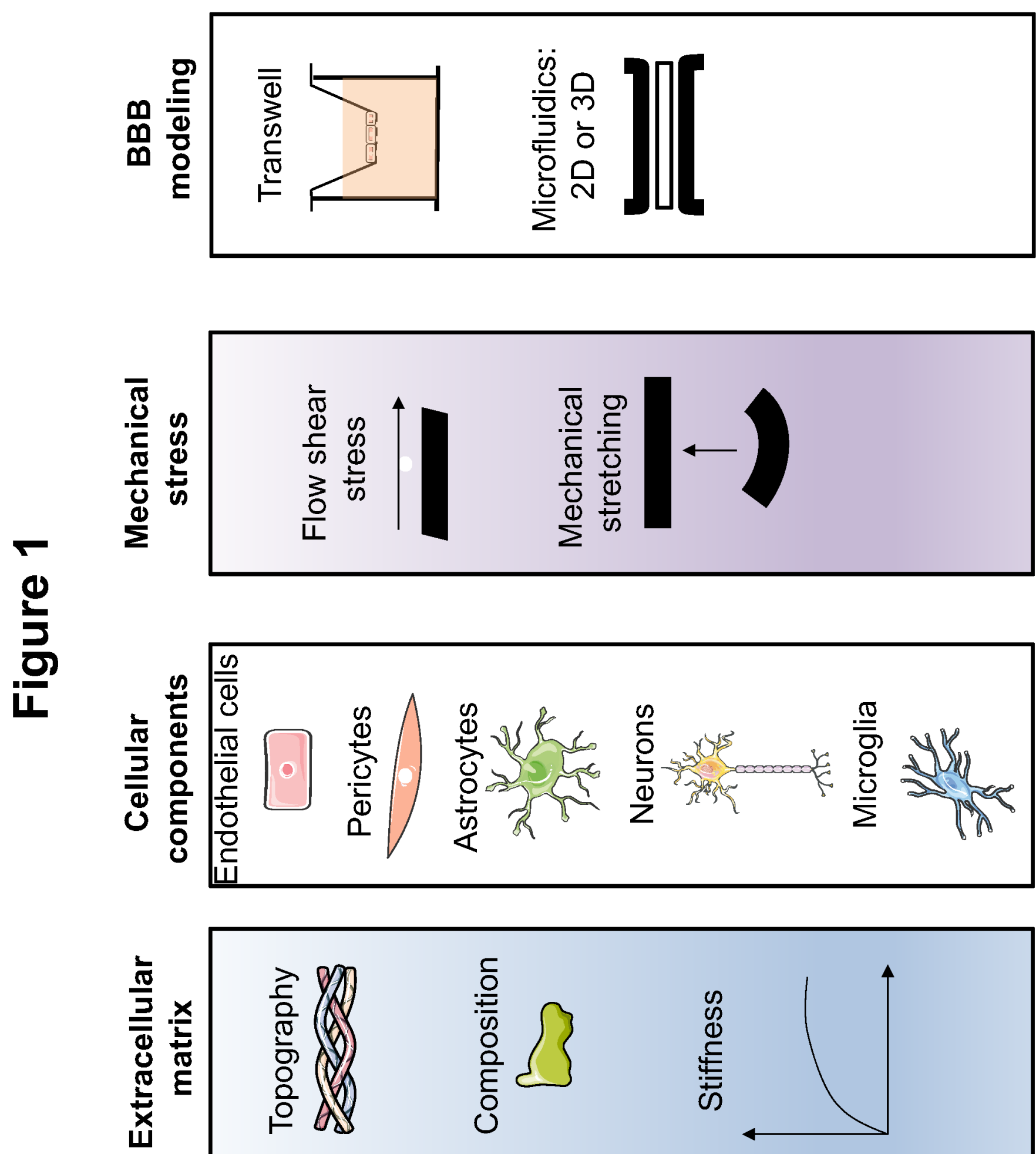


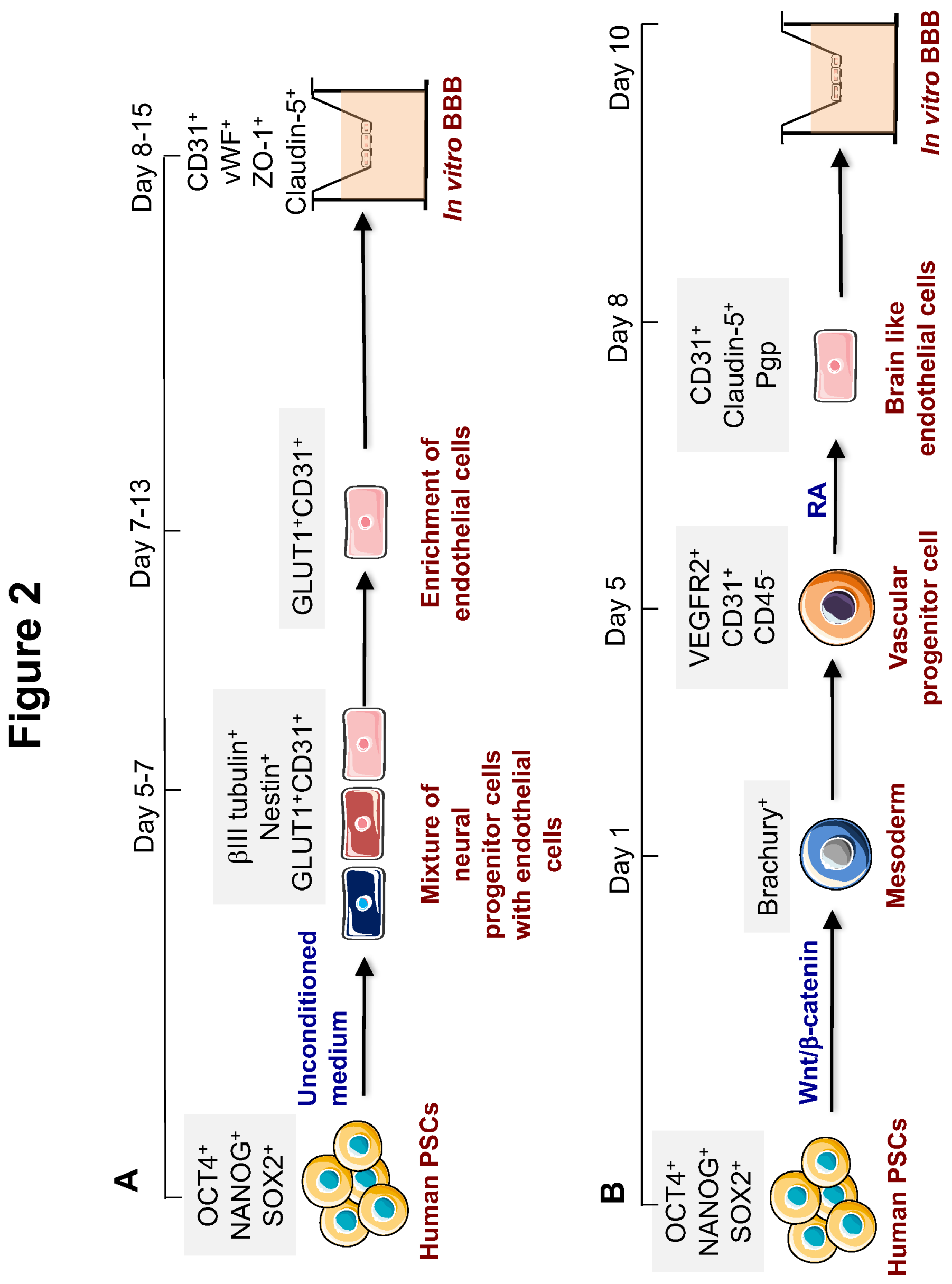

URL: http://mc.manuscriptcentral.com/eodc Email: IEDC-peerreview@journals.tandf.co.uk 


\section{Figure 3}

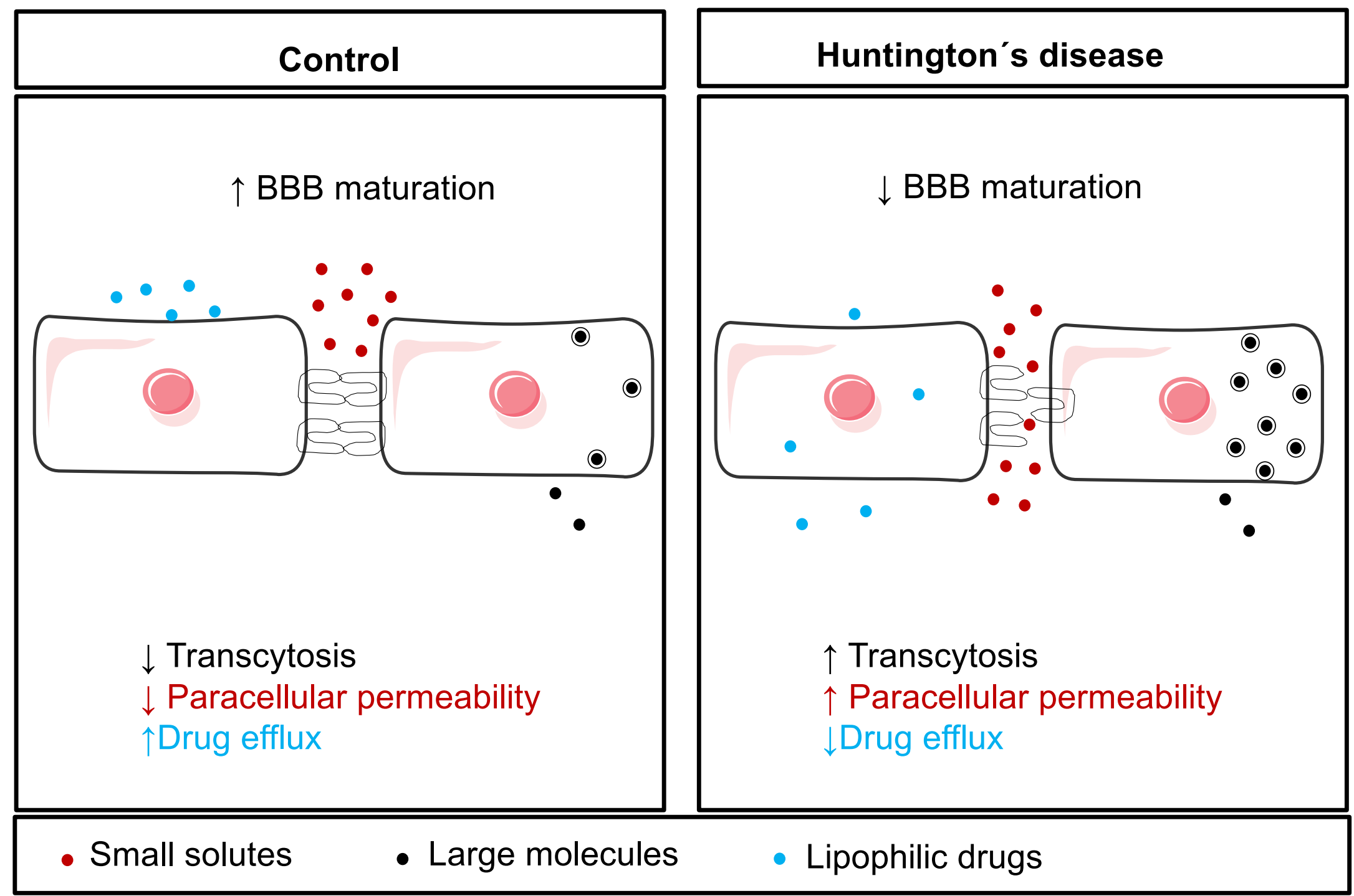




\section{Figure 4}

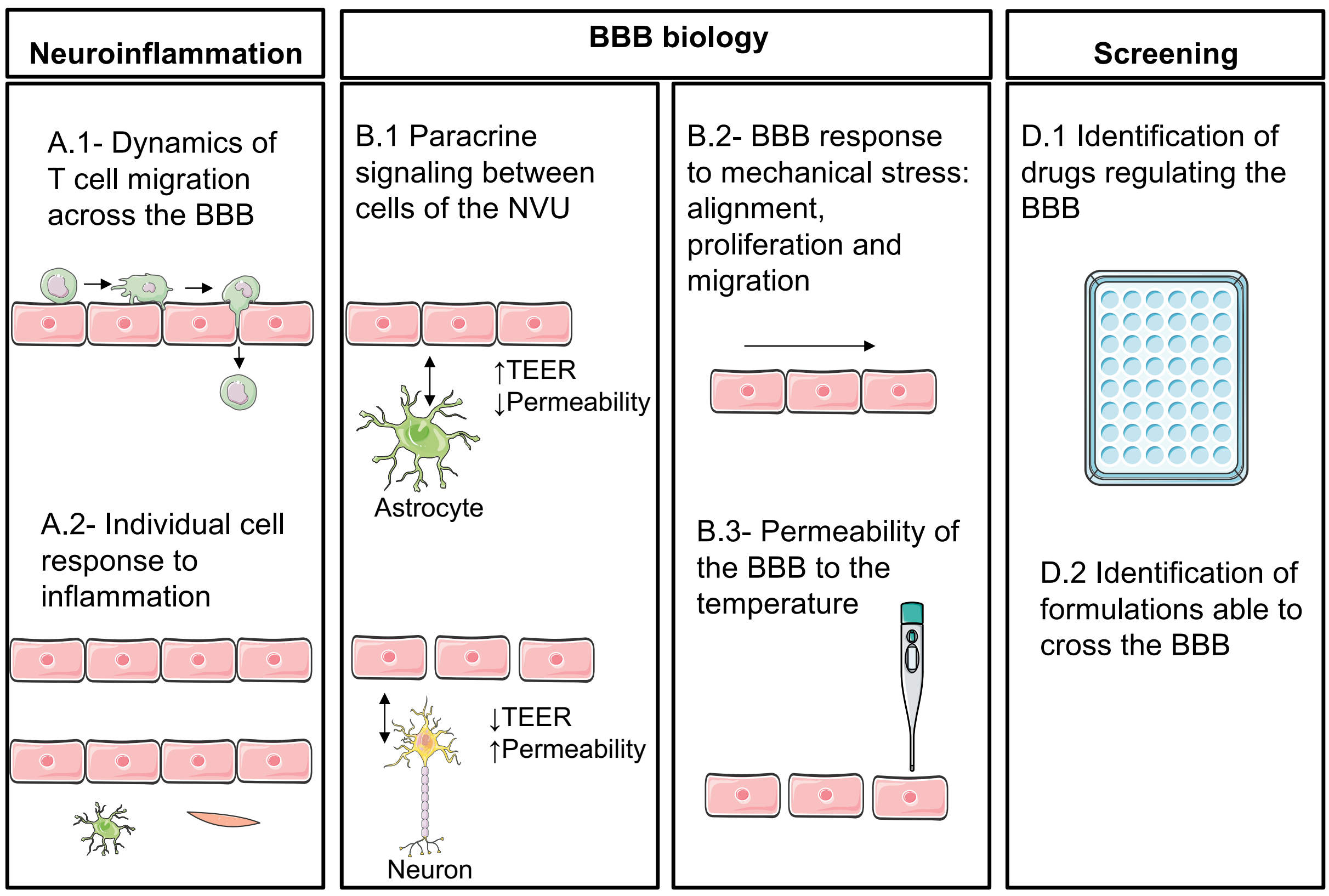

